\title{
Comparison of electronic brachytherapy and Mohs micrographic surgery for the treatment of early-stage non-melanoma skin cancer: a matched pair cohort study
}

\author{
Rakesh Patel, MD!, Robert Strimling, MD², Stephen Doggett, MD³, Mark Willoughby, MD², Kenneth Miller, MD5, \\ Lawrence Dardick, MD6. Erick Mafong, MD \\ 'Good Samaritan Radiation Oncology, Los Gatos, CA, 2Strimling Dermatology, Laser Vein Institute, Las Vegas, NV, ${ }^{3}$ Aegis Oncology, Tustin, CA \\ ${ }^{4}$ San Diego Dermatology and Laser Institute, San Diego, CA, ${ }^{5}$ Miller Dermatology, Los Gatos, CA, ${ }^{6}$ Berman Skin Institute, Placerville, CA, \\ ${ }^{7}$ San Diego Dermatology and Laser Center, San Diego, CA, USA
}

\begin{abstract}
Purpose: High-dose-rate electronic brachytherapy (EBT) provides a non-surgical treatment option for non-melanoma skin cancer (NMSC). This matched-pair cohort study compared the outcomes of treatment with EBT to those of Mohs micrographic surgery (MMS) in patients with NMSC.

Material and methods: At four treatment centers, patients treated with EBT were case matched to patients treated with MMS based on retrospectively-collected patient age, lesion size, location and type, and year of treatment. Follow-up data were prospectively collected and included local recurrence, toxicities, cosmesis, and patient-reported outcomes.

Results: The 369 patients (188 in the EBT treatment group and 181 in the MMS treatment group) had 416 lesions (208 in the EBT group and 208 in the MMS group), including 226 basal cell carcinomas (BCC) and 190 squamous cell carcinomas (SCC). Most patients were Caucasian (98.9\% and $99.5 \%$ ) and male $(65.4 \%$ and $66.3 \%)$ of median age 80.7 (range: 61-98) (EBT) and 76.8 (range: 51-98) years (MMS). Most lesions were size $>1 \mathrm{~cm}$ and $\leq 2 \mathrm{~cm}$, and located on the head. At mean 3.4 years post-treatment, $99.5 \%$ of EBT, and $100.0 \%$ of MMS-treated lesions were free of recurrence $(p=n s)$. One recurrence was noted in the EBT group. Physicians rated cosmesis as "excellent" or "good" in 97.6\% of EBT-treated lesions, and 95.7\% of MMS-treated lesions.

Conclusions: This matched-pair cohort study supports the use of EBT as an effective non-surgical treatment option for NMSC with equivalent recurrence rates and cosmetic outcomes to MMS in appropriately-selected patients with early stage NMSC at extended follow-up.

Key words: electronic brachytherapy, Mohs micrographic surgery, NMSC.

\section{Purpose}

Nonmelanoma skin cancer (NMSC) rates are increasing worldwide [1]. The United States has approximately 5.4 million cases [2,3], with treatment costs of 8.1 billion dollars annually [3]. While mortality rates are low, untreated NMSC can further invade and destroy skin and tissue, rendering treatment more difficult and outcomes less favorable [4]. Nonmelanoma skin cancer significantly affects quality of life, causing anxiety and isolating behaviors, particularly in patients with facial lesions [5]. Consequently, identifying treatment modalities that are both effective for patients and cost effective is imperative.
Surgical options for NMSC removal include curettage with electrodessication, surgical excision, and Mohs micrographic surgery (MMS), with MMS recommended for tumors at higher risk for recurrence [6,7]. A typical procedure can last 2 to 4 hours, and more complicated cases may take longer. Tumor recurrence at five years after MMS is $<5 \%$ for basal cell carcinomas (BCC) and $6 \%$ for squamous cell carcinomas (SCC) $[6,7,8,9]$. Mohs micrographic surgery generally yields excellent cosmetic results with minimal adverse outcomes $[6,7,10]$. A disadvantage to surgical excision is the potential for disfigurement and/or functional defects when the cancer is located in 
high-risk areas, such as the eyes, nose, lips, or on thin skin overlying bony prominences or tendons. Radiation therapy (RT) for cancer eradication at these sites may result in improved cosmetic and functional outcomes without the need for tissue removal or skin grafting [11]. Radiation therapy may be an effective alternative for patients who are not suitable candidates for surgery due to age, general health, or personal preference $[12,13]$.

Radiation therapy, using superficial orthovoltage $\mathrm{X}$-rays and electron therapy, has outcomes comparable to MMS, with low complication rates and good to excellent cosmetic results $[14,15,16,17]$. HDR brachytherapy with an iridium-based source has shown a $98 \%$ control rate at a median follow-up of 5 years [18], and a $92 \%$ control rate at 10 years [19]. High-dose-rate brachytherapy delivered over a hypofractionated schedule offers the potential for improved cosmesis and fewer late toxicities compared with traditional radiotherapy due to decreased exposure of healthy tissue [1]. HDR brachytherapy, using an electronic source (EBT) for the treatment of NMSC, has shown promising early results $[12,20,21,22]$ with respect to recurrence, complications, and cosmetic results, and provides a safety advantage to the patient and healthcare provider in avoiding the use of radioactive isotopes $[20,21,22,23]$. As part of an effort to develop appropriate use criteria for EBT, a clinical study was undertaken to compare the long-term local recurrence, toxicities, and cosmetic outcomes with EBT and MMS for the treatment of early-stage NMSC. The sites participating in this study commonly offer the options to patients to be treated with either EBT or MMS. Therefore, patients treated with EBT were clinically matched to patients treated with MMS at four treatment centers and evaluated at 2.3 to 5.0 years post-treatment.

\section{Material and methods}

The protocol was approved by an independent central institutional review board. This study included both a retrospective chart review, and a prospective collection and analysis of follow-up data. Patients signed an informed consent form prior to participation in this study.

\section{Patient selection}

All patients who had already received EBT for NMSC at 4 treatment centers and met the eligibility criteria were invited to participate. The EBT participants were individually matched with MMS patients based on patient age (within 15 years), lesion size, type and location, and treatment dates. All MMS subjects treated in the same timeframe were considered for matching; the final pair was selected to achieve the closest match of demographics and lesion characteristics. Successfully matched pairs were included in the study. Additional eligibility criteria included: completion of EBT or MMS for NMSC $\geq 3$ years prior to enrollment; age > 40 years; pathological diagnosis confirmed to be SCC or BCC prior to treatment; cancer stage $0-2$ [24]. Exclusion criteria included: target area adjacent to a burn scar; surgical resection of the cancer prior to EBT; presence of actinic keratosis; known metastatic disease.

\section{Treatment methods}

EBT was performed using the $\mathrm{Xoft}^{\circledR}$ Axxent ${ }^{\circledR}$ Electronic Brachytherapy System ${ }^{\circledR}$ (Xoft, Inc., A Subsidiary of iCAD, Inc. San Jose, CA), which utilizes a miniature, HDR, low energy electronic X-ray source, similar in dose characteristics to HDR brachytherapy using an Iridium (Ir-192) source. Standard surface applicators (Xoft, Inc.), including sizes $10,20,35$, and $50 \mathrm{~mm}$ in diameter, were used to cover the lesions with a 2.0-5.0 mm surface margin. A prescription dose of 40.0 Gy in 8 fractions (5 Gy twice weekly) was delivered to a typical dose depth of 2-3 $\mathrm{mm}$ or in some cases a customized dose, depth, or schedule was used. The treatment methodology has been previously reviewed $[13,25,26]$. MMS was performed by clinicians who had completed Mohs fellowship training, and surgeries were conducted according to guidelines of the American College of Mohs Surgery [27].

\section{Study endpoints}

Diagnosis and staging of lesions had been completed prior to treatment based on a tissue biopsy by a dermatologist at each site; the dermatologist then referred patients for EBT or MMS based on patient and lesion characteristics. Treatment data and lesion characteristics at the time of treatment were collected retrospectively in this study during a chart review. Data for the primary and secondary endpoints of this study were collected prospectively at an office visit, during which patients were clinically evaluated by the physician who had conducted the EBT or MMS, and each participant completed a questionnaire.

The primary endpoint was the absence of local recurrence during the follow-up period. Secondary endpoints included long-term toxicities, cosmetic outcomes, and patient satisfaction with treatment. Physicians specifically assessed the presence or absence of the following toxicities: hypopigmentation, hyperpigmentation, erythematous scar, telangiectasia, hair loss, fibrosis, atrophy, loss of subcutaneous tissue, hypertrophy (excessive fibrosis) or keloid, and poor healing, ulceration, or erosion. Cosmetic outcomes were rated by both physicians and patients using a standardized scale adapted from Cox et al., including ratings of poor (ulceration, necrosis, erosion), fair (marked atrophy, marked discoloration, marked textural changes), good (no atrophy to minimal atrophy, slight discoloration, slight textural changes), and excellent (barely visible changes) [28]. Patients completed a standardized questionnaire evaluating satisfaction with treatment. The 12 questions had six possible responses ranging from "strongly disagree" to "strongly agree". Responses were given a value of $0-5$, and values were totalled for an overall score.

\section{Statistical analysis}

The comparisons between treatment groups for recurrence of NMSC was tested using Fisher's exact test, and cosmetic outcomes were tested using two-sided $\chi^{2}$ tests. The between-group difference in total score for a patient reported satisfaction questionnaire was tested using a Kruskal-Wallis non-parametric test. The signif- 
Table 1. Patient demographics at time of treatment

\begin{tabular}{|c|c|c|c|}
\hline \multicolumn{2}{|l|}{ Variable } & EBT & MMS \\
\hline \multicolumn{2}{|c|}{ Number of patients (\%) } & 188 & 181 \\
\hline \multirow{2}{*}{$\begin{array}{l}\text { Age } \\
\text { (years) }\end{array}$} & Median & 80.7 & 76.8 \\
\hline & Range & $61.1-98.0$ & $51.4-98.4$ \\
\hline \multirow[t]{2}{*}{ Gender } & Male & $123(65.4 \%)$ & $120(66.3 \%)$ \\
\hline & Female & $65(34.6 \%)$ & $61(33.7 \%)$ \\
\hline \multirow[t]{3}{*}{ Ethnicity } & Caucasian/Non-Hispanic & $186(98.9 \%)$ & $180(99.5 \%)$ \\
\hline & African-American & $0(0.0 \%)$ & $1(0.5 \%)$ \\
\hline & Asian/Pacific Islander & $2(1.1 \%)$ & $0(0.0 \%)$ \\
\hline \multirow{6}{*}{$\begin{array}{l}\text { Prior skin } \\
\text { cancer }\end{array}$} & Prior skin cancer & $147(78.2 \%)$ & $136(75.1 \%)$ \\
\hline & \multicolumn{3}{|l|}{ Types: } \\
\hline & Melanoma & $13(6.9 \%)$ & $8(4.4 \%)$ \\
\hline & $\mathrm{BCC}$ & $135(71.8 \%)$ & $114(63.0 \%)$ \\
\hline & SCC & $105(55.9 \%)$ & 97 (53.6\%) \\
\hline & $\mathrm{BSC}$ & $1(0.5 \%)$ & $0(0.0 \%)$ \\
\hline \multicolumn{2}{|c|}{$\begin{array}{l}\text { Prior surgery or treatment } \\
\text { of another lesion }\end{array}$} & $57(30.3 \%)$ & $124(68.5 \%)$ \\
\hline
\end{tabular}

icance level was set at 0.05. Analyses were performed using SAS software (Version 9, SAS Institute, Inc., Cary, NC, USA).

\section{Results}

\section{Patient demographics and lesion characteristics}

The study enrolled 369 patients, of mean age 80.7 and 76.8 years in the EBT and MMS groups, respectively (Table 1). The 369 patients had 416 lesions, 113 in each treatment group were BCC and 95 in each group were SCC. All patients completed all evaluations. The majority $(70.2 \%)$ of lesions were $>1 \mathrm{~cm}$ and $\leq 2 \mathrm{~cm}(70.2 \%)$, and were stage 0 or 1 (Table 2). Patient and lesion characteristics were well matched between treatment groups. Most patients in the EBT group received a 40 Gy dose over 8 fractions (5 Gy/fraction twice weekly; Table 3). Most patients in the MMS group required 1 stage/level (Table 4).

\section{NMSC recurrence}

Follow-up visits occurred at a mean time from treatment of 3.3 (range: 2.6-4.3) years for EBT and 3.5 (range: 2.3-5.0) years for MMS, and nearly all patients were free of local recurrence (Table 5). One recurrence was noted in the EBT group: 1 BCC tumor on the cheek of a 75-year old patient. The recurrence occurred at 1 year post-treatment

Table 2. Lesion characteristics at time of treatment

\begin{tabular}{|c|c|c|c|}
\hline \multicolumn{2}{|l|}{ Variable } & EBT & MMS \\
\hline \multicolumn{2}{|c|}{ Number of lesions (\%) } & 208 & 208 \\
\hline \multirow[t]{2}{*}{ Histopathology } & $\mathrm{BCC}$ & $113(54.3 \%)$ & $113(54.3 \%)$ \\
\hline & SCC & $95(45.7 \%)$ & $95(45.7 \%)$ \\
\hline \multirow[t]{3}{*}{ Cancer staging 1} & Stage 0: Tis, NO, MO & $101(48.6 \%)$ & $76(36.5 \%)$ \\
\hline & Stage 1: T1, NO, MO & $103(49.5 \%)$ & $129(62.0 \%)$ \\
\hline & Stage 2: T2, NO, MO \& $\leq 4 \mathrm{~cm}$ in diameter & $4(1.9 \%)$ & $3(1.4 \%)$ \\
\hline \multirow[t]{3}{*}{ Lesion size $(\mathrm{cm})$} & $\leq 1 \mathrm{~cm}$ & $57(27.4 \%)$ & $57(27.4 \%)$ \\
\hline & $>1 \mathrm{~cm}$ and $\leq 2 \mathrm{~cm}$ & $146(70.2 \%)$ & $146(70.2 \%)$ \\
\hline & $>2 \mathrm{~cm}$ and $\leq 3 \mathrm{~cm}$ & $5(2.4 \%)$ & $5(2.4 \%)$ \\
\hline \multirow[t]{10}{*}{ Lesion location } & Head & $5(2.4 \%)$ & $5(2.4 \%)$ \\
\hline & Ear & $10(4.8 \%)$ & $10(4.8 \%)$ \\
\hline & Eyelid & $5(2.4 \%)$ & $5(2.4 \%)$ \\
\hline & Face/Neck & $72(34.6)$ & $72(34.6)$ \\
\hline & Lip & $4(1.9 \%)$ & $4(1.9 \%)$ \\
\hline & Scalp & $14(6.7 \%)$ & $14(6.7 \%)$ \\
\hline & Nose & $33(15.9 \%)$ & $33(15.9 \%)$ \\
\hline & Torso & $12(5.8 \%)$ & $12(5.8 \%)$ \\
\hline & Lower extremity & $23(11.1 \%)$ & 23 (11.1\%) \\
\hline & Upper extremity & 30 (14.4\%) & $30(14.4 \%)$ \\
\hline
\end{tabular}

${ }^{1}$ Cancer Staging System of the American Joint Committee on Cancer [24]

EBT - electronic brachytherapy, MMS - Mohs micrographic surgery, BCC - basal cell carcinoma, SCC-squamous cell carcinoma, $T$ - tumor, N-nodes (lymph), M - metas tases, $G$ - grade 
Table 3. Treatment characteristics for electronic brachytherapy (EBT)

\begin{tabular}{lcc} 
Number of lesions (\%) & \multicolumn{2}{c}{208} \\
\hline Applicator size (mm) & 10 & $78(37.5 \%)$ \\
\cline { 2 - 3 } & 20 & $103(49.5 \%)$ \\
\cline { 2 - 3 } & 35 & $25(12.0 \%)$ \\
\hline Total received dose (Gy) & 30 & $2(1.0 \%)$ \\
\cline { 2 - 3 } & 32 & $5(2.4 \%)$ \\
\cline { 2 - 3 } & 36 & $1(0.5 \%)$ \\
\hline Number of fractions & 40 & $207(99.5 \%)$ \\
\hline Dose per fraction (Gy) & $8 / 8$ & $1(0.5 \%)$ \\
\cline { 2 - 3 } & $10 / 10$ & $10(95.2 \%)$ \\
\hline & 4 & $14(6.7 \%)$ \\
\hline & 5 & $1(0.5 \%)$ \\
\hline
\end{tabular}

and the cancer was resected. There was no statistically significant difference in recurrence rates between the two groups (Fisher's exact test $p$-value $=1.000$ ).

\section{Safety and toxicity}

The majority of patients had "no changes, relatively invisible scar" (Table 6). The most common toxicity was hypopigmentation, observed in $59.6 \%$ of patients in the EBT group and $52.4 \%$ in the MMS group. Most toxicities occurred at a similar rate in both groups. There was a higher rate of telangiectasia with EBT relative to MMS (31.4\% vs. $11.1 \%)$.

\section{Cosmesis}

Physicians rated cosmesis of the treatment sites as "excellent" or "good" in 98\% of EBT-treated lesions and $96 \%$ of MMS-treated lesions. These rates were not statistically significantly different between the treatment groups

Table 5. Primary endpoint: absence of local recurrence at follow-up visit

\begin{tabular}{|c|c|c|c|}
\hline \multirow{2}{*}{\multicolumn{2}{|c|}{ Number of lesions (\%) }} & EBT & MMS \\
\hline & & 208 & 208 \\
\hline \multicolumn{2}{|c|}{ Absence of local recurrence } & 207 (99.5\%) & 208 (100.0\%) \\
\hline \multicolumn{2}{|l|}{$95 \% \mathrm{Cl}$} & $97.4-100 \%$ & $98.2-100 \%$ \\
\hline \multicolumn{2}{|c|}{$\begin{array}{l}p \text {-value } \\
\text { (Fisher's exact test) }\end{array}$} & \multicolumn{2}{|c|}{1.000} \\
\hline \multirow{3}{*}{$\begin{array}{l}\text { Follow-up } \\
\text { time (years) }\end{array}$} & Mean \pm Std & $3.3 \pm 0.4$ & $3.5 \pm 0.5$ \\
\hline & Median & 3.2 & 3.4 \\
\hline & Range & $2.6-4.3$ & $2.3-5.0$ \\
\hline
\end{tabular}

Table 4. Treatment characteristics for Mohs micrographic surgery (MMS)

\begin{tabular}{|c|c|c|}
\hline Number of lesions (\%) & \multicolumn{2}{|c|}{$n=208$} \\
\hline \multirow{3}{*}{$\begin{array}{l}\text { Stages/Levels required } \\
\text { for clear margins }\end{array}$} & 1 & $177(85.1 \%)$ \\
\hline & 2 & $30(14.4 \%)$ \\
\hline & 3 & $1(0.5 \%)$ \\
\hline \multirow[t]{2}{*}{ Closure method } & Surgical closure & $192(92.3 \%)$ \\
\hline & Secondary intension & $16(7.7 \%)$ \\
\hline
\end{tabular}

$\left(\chi^{2} p\right.$-value $\left.=0.277\right)$. Cosmesis ratings by patients were "excellent" or "good" in $90 \%$ of EBT-treated sites and 95\% of MMS-treated sites (Table 7).

\section{Patient questionnaire}

In the EBT group, mean scores for each of the 12 questions ranged from 4.1 to 5.0 with individual scores covering the range of possible responses (0 to 5). In the MMS group, mean scores ranged from 4.6 to 4.8 with individual scores covering the full range ( 0 to 5 ). In both treatment groups, the median score for each of the 12 questions was 5, which was the maximum positive or favorable response to each question (Table 8). The median total scores for the 12 questions were 58.0 and 59.0 for the EBT and MMS groups, respectively ( $p=n s$, Kruskal-Wallis test).

\section{Discussion}

This matched-pair cohort study enrolled 188 patients with 208 lesions treated with EBT, and 181 patients with

Table 6. Long-term toxicities present at follow-up visit

\begin{tabular}{|c|c|c|}
\hline & EBT & MMS \\
\hline Number of lesions (\%) & 208 & 208 \\
\hline $\begin{array}{l}\text { No changes, } \\
\text { relatively invisible scar }\end{array}$ & $138(66.7 \%)$ & $143(68.8 \%)$ \\
\hline \multicolumn{3}{|l|}{ Late toxicities: } \\
\hline Hypopigmentation & $124(59.6 \%)$ & $109(52.4 \%)$ \\
\hline Hyperpigmentation & $11(5.3 \%)$ & $4(1.9 \%)$ \\
\hline Erythematous scar & $6(2.9 \%)$ & $15(7.2 \%)$ \\
\hline Telangiectasia & $65(31.4 \%)$ & $23(11.1 \%)$ \\
\hline Hair loss & $8(3.9 \%)$ & $7(3.4 \%)$ \\
\hline Fibrosis & $3(1.4 \%)$ & $2(1.0 \%)$ \\
\hline Atrophy & $12(5.8 \%)$ & $9(4.3 \%)$ \\
\hline Loss of subcutaneous tissue & $7(3.4 \%)$ & $6(2.9 \%)$ \\
\hline $\begin{array}{l}\text { Hypertrophy (excessive } \\
\text { fibrosis) or Keloid }\end{array}$ & $0(0.0 \%)$ & $3(1.4 \%)$ \\
\hline $\begin{array}{l}\text { Poor healing, ulceration, } \\
\text { erosion }\end{array}$ & $4(1.9 \%)$ & $0(0.0 \%)$ \\
\hline
\end{tabular}

EBT - electronic brachytherapy, MMS - Mohs micrographic surgery 
Table 7. Secondary endpoint: cosmesis grade at follow-up visit

\begin{tabular}{|c|c|c|c|}
\hline & & EBT & MMS \\
\hline \multicolumn{2}{|c|}{ Number of lesions (\%) } & 208 & 208 \\
\hline \multicolumn{2}{|c|}{$\begin{array}{l}\text { Clinician cosmetic grade } \\
\text { excellent/good }\end{array}$} & $203(97.6 \%)$ & 199 (95.7\%) \\
\hline \multicolumn{2}{|l|}{$95 \% \mathrm{Cl}$} & $94.5-99.2 \%$ & $92.0-98.0 \%$ \\
\hline \multicolumn{2}{|l|}{$p$-value ( $\chi^{2}$ test $)$} & \multicolumn{2}{|c|}{0.277} \\
\hline \multirow{4}{*}{$\begin{array}{l}\text { Clinician cosmesis } \\
\text { grade }^{1}\end{array}$} & Excellent & $133(63.9 \%)$ & $142(68.3 \%)$ \\
\hline & Good & 70 (33.7\%) & $57(27.4 \%)$ \\
\hline & Fair & $1(0.5 \%)$ & $9(4.3 \%)$ \\
\hline & Poor & $4(1.9 \%)$ & $0(0.0 \%)$ \\
\hline \multirow{4}{*}{$\begin{array}{l}\text { Subject cosmesis } \\
\text { grade }^{1}\end{array}$} & Excellent & $140(67.3 \%)$ & $148(71.1 \%)$ \\
\hline & Good & $48(23.1 \%)$ & $50(24.0 \%)$ \\
\hline & Fair & $15(7.2 \%)$ & $10(4.8 \%)$ \\
\hline & Poor & $5(2.4 \%)$ & $0(0.0 \%)$ \\
\hline
\end{tabular}

${ }^{1}$ Adapted from Cox et al. [28]

208 lesions treated with MMS for NMSC. At a mean post-treatment follow-up of 3.4 years, recurrence rates were not statistically different, with $99.5 \%$ (EBT) and $100.0 \%$ (MMS) of lesions free of recurrence $(p=n s)$. Late toxicities were specifically assessed, which helped to increase reporting and fully elucidate the safety profile. The range of toxicities was consistent with expected late toxicities with EBT and MMS. The overall incidence of toxicities was similar in both arms, with low rates of the more clinically significant side effects such as poor healing, ulceration, atrophy, and fibrosis. Telangiectasia was more common with EBT-treated lesions than with MMS-treated lesions. Cosmetic results were also similar between the two treatments. Physician-rated cosmesis was "good" or "excellent" in 97.6\% of EBT-treated lesions, and 95.7\% of MMS-treated lesions. Patient-rated cosmesis was consistent with physician ratings although slightly lower. Patient responses to the questionnaire were remarkably consistent across the 12 questions, indicating a high level of satisfaction in both treatment groups.

These results are consistent with and add to the existing body of clinical research supporting the use of EBT for the treatment of NMSC. Bhatnagar reported outcomes for 297 lesions with up to 63 months follow-up (mean: 16.5; range: 1-63 months) [12], with only one recurrence and excellent cosmesis in $100 \%$ of patients at years $4-5$. No acute toxicities were reported past year 1, and late toxicities occurred in $2 \%$ of patients. Doggett et al. reported a series of 524 lesions treated with EBT, with a mean follow-up of 12.5 months. The local recurrence rate was $0.7 \%$ [29]. Parvati et al. retrospectively analyzed 157 NMSC lesions treated with EBT with 3.4 to 34.8 months of follow-up, and 2 recurrences were noted (at 6.3 and 7.3 months) [22]. Excellent cosmesis was rated in $94.2 \%$ of cases. Overall, control rates and cosmetic results re-
Table 8. Results of patient satisfaction questionnaire at follow-up visit

\begin{tabular}{|c|c|c|}
\hline Total score & EBT, $n=208$ & MMS, $n=208$ \\
\hline Mean \pm SD & $54.0 \pm 9.0$ & $56.0 \pm 5.3$ \\
\hline Median [range] & $58.0[10-60]$ & 59.0 [38-60] \\
\hline \multicolumn{3}{|l|}{ Individual questions ${ }^{1}$} \\
\hline $\begin{array}{l}\text { Treatments were convenient } \\
(5=\text { strongly agree) }\end{array}$ & $\begin{array}{l}4.3 \pm 1.1 \\
5.0[0-5]\end{array}$ & $\begin{array}{l}4.7 \pm 0.6 \\
5.0[2-5]\end{array}$ \\
\hline $\begin{array}{l}\text { Satisfied with how well } \\
\text { treatment worked } \\
(5=\text { strongly agree })\end{array}$ & $\begin{array}{l}4.5 \pm 1.0 \\
5.0[0-5]\end{array}$ & $\begin{array}{l}4.8 \pm 0.5 \\
5.0[1-5]\end{array}$ \\
\hline $\begin{array}{l}\text { Satisfied with appearance of } \\
\text { the treated area } \\
(5=\text { strongly agree })\end{array}$ & $\begin{array}{l}4.4 \pm 1.0 \\
5.0[0-5]\end{array}$ & $\begin{array}{l}4.6 \pm 0.7 \\
5.0[2-5]\end{array}$ \\
\hline $\begin{array}{l}\text { If another cancer, would use } \\
\text { same treatment } \\
\text { ( } 5 \text { = strongly agree) }\end{array}$ & $\begin{array}{l}4.1 \pm 1.4 \\
5.0[0-5]\end{array}$ & $\begin{array}{c}4.6 \pm 0.7 \\
5.0[1-5]\end{array}$ \\
\hline $\begin{array}{l}\text { Have not had any skin } \\
\text { problems with treated area } \\
\text { ( } 5=\text { strongly agree) }\end{array}$ & $\begin{array}{l}4.5 \pm 1.2 \\
5.0[0-5]\end{array}$ & $\begin{array}{l}4.7 \pm 0.6 \\
5.0[1-5]\end{array}$ \\
\hline $\begin{array}{l}\text { Since treatment, frustrated } \\
\text { about appearance of treated } \\
\text { site ( } 5 \text { = strongly disagree) }\end{array}$ & $\begin{array}{l}4.5 \pm 1.1 \\
5.0[0-5]\end{array}$ & $\begin{array}{l}4.6 \pm 1.0 \\
5.0[0-5]\end{array}$ \\
\hline $\begin{array}{l}\text { Since treatment, embar- } \\
\text { rassed about appearance } \\
\text { of treated site } \\
(5=\text { strongly disagree })\end{array}$ & $\begin{array}{l}4.6 \pm 0.9 \\
5.0[0-5]\end{array}$ & $\begin{array}{l}4.7 \pm 0.7 \\
5.0[1-5]\end{array}$ \\
\hline $\begin{array}{l}\text { Since treatment, depressed } \\
\text { about appearance of treated } \\
\text { site ( } 5=\text { strongly disagree })\end{array}$ & $\begin{array}{l}4.5 \pm 1.1 \\
5.0[0-5]\end{array}$ & $\begin{array}{l}4.6 \pm 0.8 \\
5.0[0-5]\end{array}$ \\
\hline $\begin{array}{l}\text { Treatment prevented me } \\
\text { from participating in daily } \\
\text { activities ( } 5=\text { strongly } \\
\text { disagree) }\end{array}$ & $\begin{array}{l}4.6 \pm 0.9 \\
5.0[0-5]\end{array}$ & $\begin{array}{l}4.6 \pm 0.9 \\
5.0[0-5]\end{array}$ \\
\hline $\begin{array}{l}\text { Treatment made it hard to } \\
\text { work or do what I enjoy } \\
(5=\text { strongly disagree })\end{array}$ & $\begin{array}{l}4.7 \pm 0.7 \\
5.0[0-5]\end{array}$ & $\begin{array}{l}4.6 \pm 0.8 \\
5.0[0-5]\end{array}$ \\
\hline $\begin{array}{l}\text { Would recommend treat- } \\
\text { ment to others }(5=\text { strongly } \\
\text { agree })\end{array}$ & $\begin{array}{l}4.4 \pm 1.3 \\
5.0[0-5]\end{array}$ & $\begin{array}{l}4.7 \pm 0.7 \\
5.0[0-5]\end{array}$ \\
\hline $\begin{array}{l}\text { Always followed instructions } \\
\text { related to care of treated } \\
\text { area ( } 5=\text { strongly agree) }\end{array}$ & $\begin{array}{c}4.9 \pm 0.4 \\
5.0[3-5]\end{array}$ & $\begin{array}{l}4.7 \pm 0.5 \\
5.0[2-5]\end{array}$ \\
\hline
\end{tabular}

${ }^{1} A$ score of 5 represents the maximum positive or favorable response to each question

$S D$ - standard deviation

ported to date with EBT have been comparable to other commonly used treatment modalities for the treatment of NMSC, including MMS, other surgical procedures, and traditional radiotherapy.

Ultimately, treatment approaches should be individualized based on specific risk factors and patient characteristics. The primary treatment goal for NMSC is to cure or eliminate the lesion with no long-term recurrence while preserving function in the region affected by cancer and 
optimizing cosmetic outcomes. Appropriate use of criteria for application of EBT in an outpatient dermatology setting have been proposed by Miller [30] and include: lesion location, where surgical distortion would be inevitable, concern for significant disfigurement, scar or keloidal formation, concern with coagulation/anticoagulant regimen, immunocompromised conditions, histories of undesirable or poor outcomes from prior skin cancer removals, patients with wound care issues, patients at risk for surgical problems, inability to withstand surgical procedures, lesions over bony prominences with risk of contractures, risks with grafts necessary for closure, lesions on the back of the hands, genitalia and lower legs, significant wound care issues, prior failure of MMS or other interventions, and superficial/multi centric basal cell carcinomas. The appropriate settings for selection of EBT over MMS or other treatment options will continue to be elucidated as additional studies are reported.

The limitations of this study include the duration of follow-up. Patients have been followed for 2.6 to 4.3 years after EBT, and 2.3 to 5 years following MMS. These patients continue to be followed, and longer-term results will be reported. Toxicities were assessed as present or not present, but were not graded, making it difficult to assess whether these late toxicities were more severe following one treatment than the other. However, the vast majority of these toxicities were acceptable to the patient and treating physician, as demonstrated in the satisfaction and cosmetic outcomes.

The matched-pair cohort study design was selected to allow evaluation of two very different treatments for NMSC in a real-world population of patients making informed, guided choices about their treatment. Thus, these results reveal the outcomes that can be anticipated when patients make choices as they do in real life. Comparison of a surgical technique with nonsurgical treatment is challenging as there are differences that cannot be controlled, and a blinded study is not possible. In addition, a randomized study trial of this size would be cost-prohibitive in a community-based practice. This study included patients who had received treatment at least 3 years prior to the study. Some of the patients in the EBT group may not have been good candidates for a surgical procedure, and likewise some patients in the MMS group may not have been appropriate candidates for EBT; consequently, a randomized study of an all-comer population of community-based patients may not be possible. The results of the study show that, in patients who are appropriately selected for each treatment, no clinically meaningful differences in outcomes with EBT and MMS were observed at a median post-treatment follow-up of 3.2 to 3.4 years, with regard to rate of recurrence, cosmesis as assessed by the physician and the patient, and patient satisfaction.

\section{Conclusions}

This matched-pair cohort study supports the use of EBT as an effective non-surgical treatment option for NMSC with equivalent recurrence rates and cosmetic outcomes to MMS in appropriately-selected patients with early stage NMSC at extended follow-up.

\section{Acknowledgements}

The authors would like to thank Dr. Ajay Bhatnagar for his role as scientific advisor. Study sponsor is Xoft, Inc., a subsidiary of iCAD, Inc. San Jose, CA. Assistance with data collection, statistical analysis, and medical writing was provided by Eminence Clinical Research, Inc. (Colorado Springs, CO, USA).

\section{Funding statement}

Study participants received compensation, funded by Xoft, for transportation and time. RS received an honorarium for speaking at a scientific conference. RP and RS are Xoft Scientific Advisory Board participants. SD, MW, $\mathrm{KM}, \mathrm{LD}$, and EM have no conflicts of interest.

Clinicaltrials.gov Identifier: NCT03024866.

\section{Disclosure}

Authors reports no conflict of interest.

\section{References}

1. Delishaj D, Rembielak A, Manfredi B et al. Non-melanoma skin cancer treated with high-dose-rate brachytherapy: a review of literature. J Contemp Brachytherapy 2016; 8: 533-540.

2. Rogers HW, Weinstock MA, Feldman SR et al. Incidence estimate of nonmelanoma skin cancer (keratinocyte carcinomas) in the U.S. population. JAMA Dermatol 2015; 151: 1081-1086.

3. Chen JT, Kempton SJ, Rao VK. The economics of skin cancer: an analysis of Medicare payment data. Plast Reconstr Surg Glob Open 2016; 4: e868.

4. Alam M, Goldberg LH, Silapunt S et al. Delayed treatment and continued growth of nonmelanoma skin cancer. J Am Acad Dermatol 2011; 64: 839-848.

5. Steenrod AW, Smyth EN, Bush EN et al. A Qualitative Comparison of Symptoms and Impact of Varying Stages of Basal Cell Carcinoma. Dermatol Ther 2015; 5: 183-199.

6. Kauvar ANB, Cronin T Jr, Roenigk R et al. Consensus for nonmelanoma skin cancer treatment: basal cell carcinoma, including a cost analysis of treatment methods. Dermatol Surg 2015; 41: 550-571.

7. Kauvar ANB, Arpey CJ, Hruza G et al. Consensus for nonmelanoma skin cancer treatment, Part II: squamous cell carcinoma, including a cost analysis of treatment methods. Dermatol Surg 2015; 41: 1214-1240.

8. Rowe DE, Carroll RJ, Day CL Jr. Mohs surgery is the treatment of choice for recurrent (previously treated) basal cell carcinoma. J Dermatol Surg Oncol 1989; 15: 424-431.

9. Rowe DE, Carroll RJ, Day CL Jr. Prognostic factors for local recurrence, metastasis, and survival rates in squamous cell carcinoma of the skin, ear, and lip. Implications for treatment modality selection. J Am Acad Dermatol 1992; 26: 976-990.

10. Gniadecki R, Glud M, Mortensen K et al. Favorable results of Mohs micrographic surgery for basal cell carcinoma. Dan Med J 2015; 62: A5171.

11. Caccialanza M, Piccinno R, Moretti D et al. Radiotherapy of carcinomas of the skin overlying the cartilage of the nose: results in 405 lesions. Eur J Dermatol 2003; 13: 462-465.

12. Bhatnagar A. Electronic brachytherapy for the treatment of non-melanoma skin cancer: results up to 4 years. Int J Radiat Oncol Biol Phys 2014; 90 Suppl: S756.

13. Kasper ME, Chaudhary AA. Novel treatment options for nonmelanoma skin cancer: focus on electronic brachytherapy. Med Devices (Auckl) 2015; 26: 493-502. 
14. Cognetta A, Howard B, Heaton $\mathrm{H}$ et al. Superficial x-ray in the treatment of basal and squamous cell carcinoma: a viable option in select patients. J Am Acad Dermatol 2012; 67: 12371241.

15. Schulte KW, Lippoid A, Auras C et al. Soft x-ray therapy for cutaneous basal cell and squamous cell carcinomas. J Am Acad Dermatol 2005; 53: 993-1001.

16. Hernández-Machin B, Borrego L, Gil-García M, Hernández BH. Office-based radiation therapy for cutaneous carcinoma: evaluation of 710 treatments. Int J Dermatol 2007; 46: 453-459.

17. Locke J, Karmpour S, Young G et al. Radiotherapy for epithelial skin cancer. Int J Radiat Oncol Biol Phys 2001; 51: 748-755.

18. Gauden R, Pracy M, Avery AM et al. HDR brachytherapy for superficial non-melanoma skin cancers. J Med Imaging Radiat Oncol 2013; 57: 212-217.

19. Köhler-Brock A, Prager W, Pohlmann S et al. The indications for and results of HDR afterloading therapy in diseases of the skin and mucosa with standardized surface applicators (the Leipzig Applicator). Strahlenther Onkol 1999; 175: 170-174.

20. Dogget $S$, Willoughby M, Willoughby $C$ et al. Incorporation of Electronic Brachytherapy for Skin Cancer into a Community Dermatology Practice. J Clin Aesthet Dermatol 2015; 8: 28-32.

21. Bhatnagar A. Nonmelanoma skin cancer treated with electronic brachytherapy: results at 1 year. Brachytherapy 2013; 12 134-140.

22. Paravati AJ, Hawkins PG, Martin AN et al. Clinical and cosmetic outcomes in patients treated with high-dose-rate electronic brachytherapy for nonmelanoma skin cancer. Pract Radiat Oncol 2015; 5: e659-e664.

23. Likhacheva AO, Devlin PM, Shirvani SM et al. Skin surface brachytherapy: A survey of contemporary practice patterns. Brachytherapy 2017; 16: 223-229.

24. American Joint Committee on Cancer. Cancer Staging System. https://cancerstaging.org/references-tools/Pages/Whatis-Cancer-Staging.aspx. Accessed: 23 November 2016.

25. Axelrod S, Kelley L, Walawalkar A et al. Dosimetric study of a new surface applicator for the Xoft Axxent system. Med Phys 2009; 36: 2532.

26. Ouhib Z, Kasper M, Perez Calatayud J et al. Aspects of dosimetry and clinical practice of skin brachytherapy: The American Brachytherapy Society working group report. Brachytherapy 2015; 14: 840-858.

27. Swanson NA. Mohs surgery: Technique, indications, applications, and the future. Arch Dermatol 1983; 119: 761-773.

28. Cox JD, Stetz J, Pajak TF. Toxicity criteria of the radiation therapy oncology group (RTOG) and the European organization for research and treatment of cancer. Int J Radiat Oncol Biol Phys 1995; 5: 1341-1346.

29. Doggett S, Brazil J, Limova M et al. Electronic brachytherapy management of atypical fibroxanthoma: report of 8 lesions. J Contemp Brachytherapy 2017; 9: 1-3.

30. Miller K. Electronic brachytherapy: understanding the technology and identifying appropriate use. Practical Dermatology $2015 ; 47-48$. 